\title{
Laboratório Virtual de Física Nuclear
}

\author{
(Virtual Laboratory on Nuclear Physics) \\ N. L. Dias, A. G. Pinheiro e G. C. Barroso \\ nildo,pinheiro,gcb(@fisica.ufc.br) \\ Departamento de Física, Universidade Federal do Ceará \\ Campus do Pici, Caixa Postal 6030, CEP - 60455-760, Fortaleza, Ce, Brasil
}

Recebido em 7 de março, 2002. Aceito em 15 de março, 2002.

\begin{abstract}
Neste Trabalho é apresentado um programa desenvolvido para simular um conjunto de equipamentos (detector e contador de radiação, fontes radioativas e placas absorvedoras) usados em um laboratório básico de Física Nuclear.
\end{abstract}

In this work it is presented a software, developed to simulate a set of equipment (probe and radiation counter, radioative sources and absorbers) that are used in a basic nuclear laboratory.

\section{Introdução}

É um fato conhecido que o ensino de física, sob o ponto de vista exclusivamente teórico, é apontado por muitos alunos como desmotivante. A utilização de laboratórios de ensino bem equipados com aparelhos modernos e em número suficiente para serem manipulados por todos os estudantes é, sem dúvida nenhuma, um sonho a ser alcançado pela maioria de nossas universidades. Assim, enquanto não alcançamos este ideal pedagógico, podemos motivar nossos alunos oferecendo, além da teoria pura e simples, a realidade virtual dos programas de simulação computacional.

Neste Trabalho, apresentamos um programa por nós desenvolvido que simula um detector de radiação tipo Geiger-Müller (GM), um contador de radiação semelhante em muitos aspectos aos contadores comerciais disponíveis $[1,2]$, três amostras radioativas e placas absorvedoras.

\section{O Programa}

O programa de instalação do Física Nuclear Virtual (FNV) (radia.exe) está disponível para download no sítio

$$
\text { www.fisica.ufc.br/brindes.htm }
$$

gratuitamente para quem quiser utilizá-lo. Após o download para sua área de trabalho, dê um duplo clique em radia.exe para iniciar a instalação. Siga os passos do programa instalador e, após instalado, vá para:

$$
>\text { Iniciar }>\text { Programas }>\text { Radiação (radiation) }
$$

Escrito em Visual Basic, o programa FNV apresenta a tela principal inicialmente como mostra a Fig. 1. Para utilizá-lo, o usuário poderá fazer uso de roteiros para práticas de física nuclear encontrados na literatura, por exemplo os das referências [3] e [4]. O professor que quiser aplicá-lo para um grupo de alunos poderá escrever seus próprios roteiros sem maiores problemas, do mesmo modo que o faz ou faria para experimentos reais. Como exemplo, fornecemos um roteiro simples para um dos experimentos possíveis de ser realizado com o FNV. Em breve, serão disponibilizados outros roteiros.

\subsection{Comandos}

Para a utilização do FNV, o usuário tem à disposição os seguintes comandos:

- Idioma: O usuário poderá optar a qualquer momento por legendas em português ou em inglês;

- Tempo: Para obter uma contagem, é necessário estabelecer primeiramente o tempo de contagem, o qual pode variar desse 1 até 600 segundos (dez minutos);

- Iniciar: Para iniciar uma contagem, pressione o botão iniciar. É possível obter contagens sem amostra, contagem de fundo;

- Pára: Interrompe a contagem em curso, quando pressionada;

- Zera: Zera o número de contagem; 


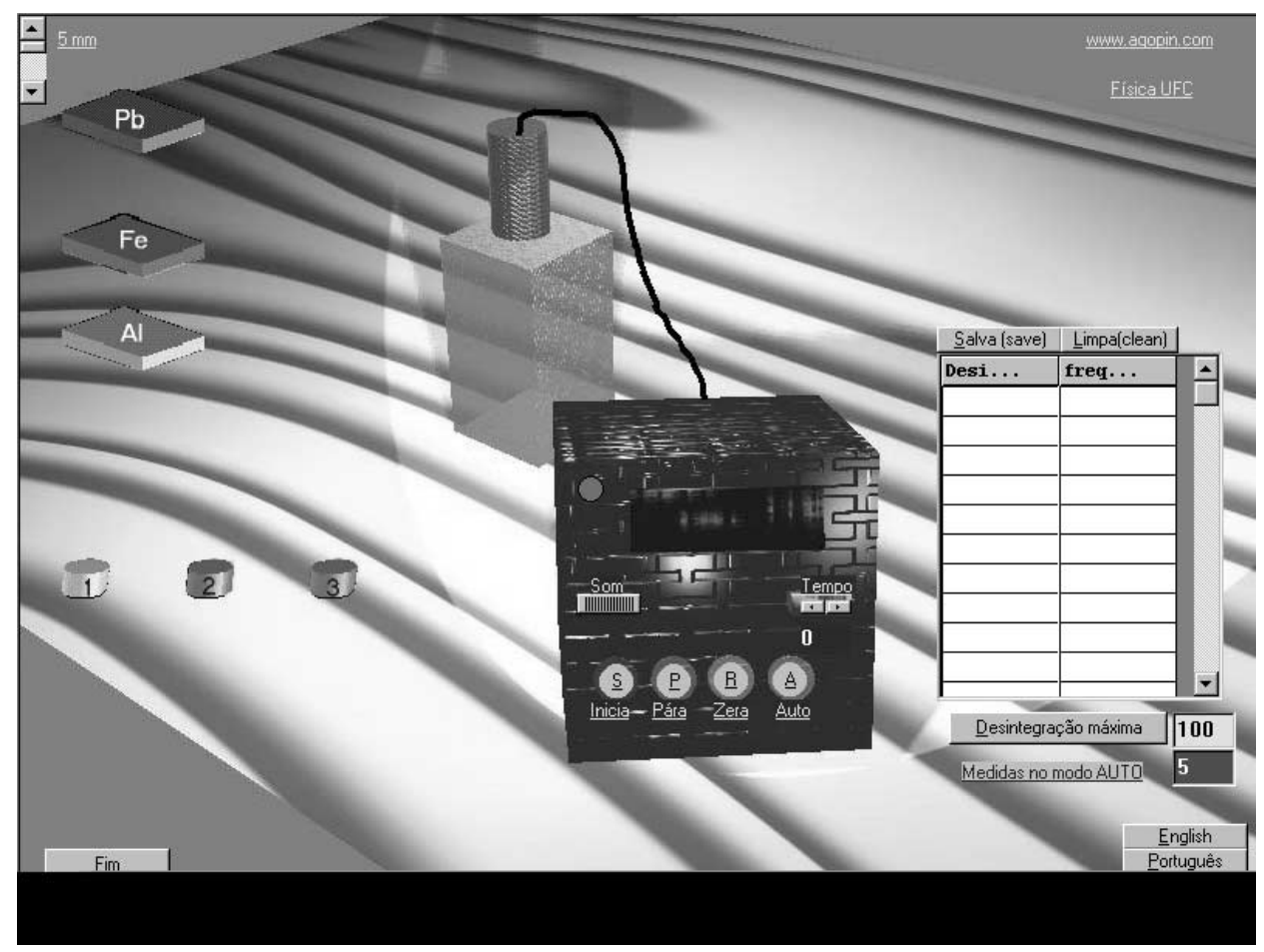

Figura 1: Aparência Inicial da tela principal.

- Auto: No modo automático, o programa realiza um número de medidas que deve ser especificado pelo operador na caixa vermelha à direita. O tempo de cada medida deve ser especificado antes de se pressionar o botão Auto. Os resultados gerados são disponibilizados em uma tabela mostrada na tela, à medida que são produzidos. Os resultados da tabela poderão ser salvos em um arquivo do tipo .txt para serem analizados posteriormente; para tanto pressione o botão salva. Escolha o nome do arquivo usando nomes diferentes para arquivos distintos;

- Desintegração máxima: Aqui o operador deve preestabelecer um número máximo de linhas que a tabela deve conter. Este número máximo deve ser tanto maior quanto maior for a atividade de sua amostra e/ou quanto maior for o tempo de contagem;

- Limpa: Este botão apaga todos os dados da tabela;

- Som: Quando utilizado, emite um som a cada desintegração;

- 1, 2, 3: Amostras radioativas com diferentes atividades, as quais podem ser arrastadas com o auxílio do mouse para a posição de medida. As desintegrações mostradas incluem a radiação de fundo;

- Pb, Fe, Al: Placas absorvedoras de chumbo, ferro ou alumínio que podem ser arrastadas com o auxílio do mouse para a caixa com o contador GM. As espessuras das placas podem variar no intervalo de $0,5 \mathrm{~cm}$ a $5,0 \mathrm{~cm}$, e o valor corrente é indicado no canto esquerdo superior da tela do computador.

- Fim: Para sair do programa.

\subsection{Resultados}

Um número é gerado aleatoriamente internamente pelo computador e, se este número estiver acima de um certo valor, dizemos que há desintegração; caso contrário não há. Desta forma, os resultados virtuais são estatisticamente semelhantes aos obtidos em experimentos reais. Na Fig. 2 é apresentado um resultado típico da freqüência versus o número de contagens para a amostra 2, sem placa absorvedora. Resultados semelhantes também são obtidos para as outras amostras. 


\subsection{Limitações}

O FNV apresenta algumas limitações em relação aos equipamentos reais, mas que julgamos não essenciais. Dentre elas destacamos:

- Não há possibilidade de se simular o ajuste de voltagem do detector GM, por isso mesmo consideraremos que o ajuste é automático;

- O tempo de resolução entre duas contagens não é especificado; por isso, será considerado muito pequeno, de modo que não haverá necessidade de se corrigir o número de contagens.

- Não há a possibilidade de se determinar a meia vida das amostras, uma vez elas apresentam sempre as mesmas características todas as vezes que simulamos as contagens;

- O tempo de contagem virtual é um pouco menor que o tempo real. Isso tem a vantagem de tornar as medidas menos massantes.

\section{Conclusões}

O programa FNV aqui apresentado não pretende substituir os equipamentos reais de física nuclear. Ele simula, em muitos aspectos, os equipamentos reais e fornece resultados semelhantes e, por isso mesmo, poderá ser usado onde não se dispõe de tais equipamentos.

Qualquer dificuldade na utilização do FNV, entre em contato com o Professor Nildo Loiola através do endereço eletrônico nildo@fisica.ufc.br. Estamos receptivos a sugestões que desde já agradecemos.

\section{Referências}

[1] Pasco Scientific, Roseville, CA, USA. (www.pasco.com).

[2] PHYWE SYSTEME GmbH, Robert-Bosch-Breite 10, Gotemberg, Alemanha, (www.phywe.com).

[3] A. Taffel, A. Baumel e L. Laudecker, Laboratory Manual - Physics - Its Methods and Meaning, Allyn and Bacon, Inc., Newton, USA (1986).

[4] C. H. Bernard e C. D. Epp, Laboratory Experiments in College Physics, John Willey \& Sons, New York, USA (1987). 


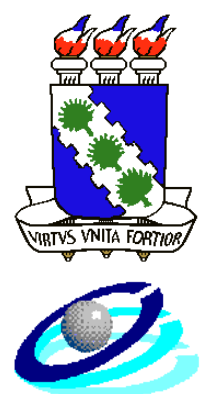

\section{MEC - UNIVERSIDADE FEDERAL DO CEARÁ CENTRO DE CIÊNCIAS - DEPARTAMENTO DE FÍSICA LABO- RATÓRIO VIRTUAL}

P R Á T I C A N $\mathbf{N}^{0}$

TÍTULO : ABSORÇÃO DE RADIAÇÃO www.fisica.ufc.br www.agopin.com OBJETIVOS:

Estudar a absorção de radiação de diversos materiais.

\section{INTRODUÇÃO:}

Nesta prática utilizaremos o programa FÍSICA NUCLEAR VIRTUAL para determinar o coeficiente de absorção linear de um dos materiais, indicados no programa. Se você desejar determinar o coeficiente dos outros materiais, proceda de maneira semelhante.

\section{TEORIA:}

Se um feixe de radiação de intensidade $\mathrm{I}_{o}$ incide sobre uma chapa de espessura d, de um determinado material, ele emergirá com uma intensidade menor I, Fig. 1. A diferença $\mathrm{I}_{o}-\mathrm{I}$ é absorvida pelo material.

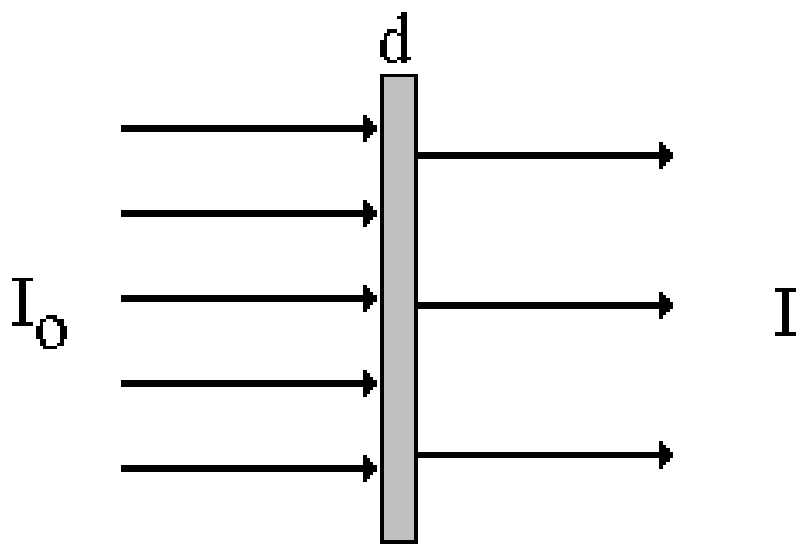

Figura 1: Placa absorvedora de espessura d.

A absorção depende da espessura d e do tipo de material usado. Pode ser mostrado que:

$$
I=I_{o} e^{-\mu d}
$$

onde $e=2,718 \ldots$ é o neperiano, e $\mu$ é o coeficiente de absorção linear do material utilizado.

Tomando-se o logaritmo natural em ambos os lados da Equação (1), temos:

$$
\ln I=\ln I_{o}-\mu d
$$

Transformando o logaritmo natural em logaritmo na base 10 , temos $(\ln N=2,3 \log N)$ :

$$
2,3 \log I=-\mu d+2,3 \log I_{o}
$$

Dividindo por 2,3, temos: 


$$
\log I=-\left(\frac{\mu}{2,3}\right) d+\log I_{o}
$$

A equação acima é do tipo $y=a x+b$ onde $-\left(\frac{\mu}{2,3}\right)$ é o coeficiente angular, e log $I_{o}$ é a interseção com o eixo y. D - PROCEDIMENTO:

Instale o programa FISICA NUCLEAR VIRTUAL a partir do sítio www.fisica.ufc.br/brindes.htm

Coloque uma amostra radioativa $(1,2$ ou 3 ) na caixa do contador Geiger-Müller (GM). Para isso, clique com o botão esquerdo do mouse sobre a amostra e, mantendo-o pressionado, arraste-a para a posição desejada.

Estabeleça o tempo de contagem; faça-o igual a $120 \mathrm{~s}$.

Faça três medidas da intensidade da radiação $\mathrm{I}_{o}$, e anote na Tabela 1 .

Escolha uma das placas absorvedoras, clique com o mouse e arraste-a para a posição de trabalho, isto é, para a caixa do detetor GM. Coloque a placa entre o contador e a amostra.

Certifique-se de que a espessura d da placa é $5 \mathrm{~mm}$. Caso seja necessário, ajuste a espessura no canto superior esquerdo da tela.

Faça três medidas da intensidade da radiação e anote na Tabela 1.

Ajuste a espessura da placa para cada valor indicado na Tabela 1 e faça três medidas da radiação.

Preencha os outros claros da Tabela 1.

Faça o gráfico de $\log I$ versus d e determine o coeficiente de absorção linear do material usado.

\begin{tabular}{|c|c|c|c|c|}
\hline & $\begin{array}{c}\text { Espessura } \\
\mathrm{d}(\mathrm{mm})\end{array}$ & $\begin{array}{c}\mathrm{I} \\
(\mathrm{cpm}) \\
\end{array}$ & $\begin{array}{l}\mathrm{I}_{\text {MÉDIO }} \\
(\mathrm{cpm})\end{array}$ & $\log \mathrm{I}_{\text {MÉDIO }}$ \\
\hline $\mathrm{I}_{\mathrm{o}}$ & zero & & & \\
\hline $\mathrm{I}_{1}$ & 5 & & & \\
\hline $\mathrm{I}_{2}$ & 10 & & & \\
\hline $\mathrm{I}_{3}$ & 20 & & & \\
\hline $\mathrm{I}_{4}$ & 30 & & & \\
\hline $\mathrm{I}_{5}$ & 40 & & & \\
\hline $\mathrm{I}_{6}$ & 50 & & & \\
\hline
\end{tabular}

Tabela 1: Resultados experimentais.

\section{E - QUESTIONÁRIO:}

1- Denomina-se meia espessura de um determinado material aquela que reduz a intensidade da radiação para a metade de seu valor inicial. Determine a meia espessura do material estudado.

2- Mostre que o coeficiente de absorção linear em função da meia espessura, $\mathrm{d}_{1 / 2}$ é dado por:

$$
\mu=\frac{0,693}{d_{1 / 2}}
$$

3- Determine o coeficiente de absorção linear usando a expressão obtida acima. 